\title{
Pentanol derivatives from basidiomycete Catathelasma imperiale and their 11ß-hydroxysteroid dehydrogenases inhibitory activity
}

\author{
Ling Zhang ${ }^{1,3}$, Yu Shen ${ }^{2}$, Hua-Jie Zhu ${ }^{1}$, Fei Wang ${ }^{1,4}$, Ying Leng ${ }^{2}$ and Ji-Kai Liu ${ }^{1}$
}

Five new secondary metabolites derived from pentanol, namely catathelasmols A-E (1-5), were isolated from the fruiting bodies of the basidiomycete Catathelasma imperiale. Their structures were elucidated on the basis of spectroscopic analysis, and the absolute configurations were determined by computational chemistry. Compounds 3,4 and 5 showed inhibitory activities against

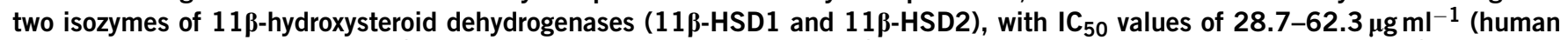

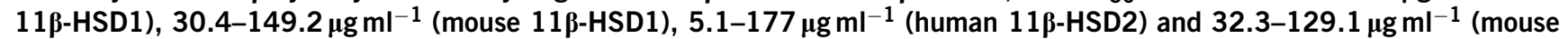
11ß-HSD2), which catalyze the interconversion of cortisol and cortisone.

The Journal of Antibiotics (2009) 62, 239-242; doi:10.1038/ja.2009.17; published online 27 March 2009

Keywords: basidiomycete; catathelasmols A-E; Catathelasma imperiale; pentanol derivatives; $11 \beta$-hydroxysteroid dehydrogenases

\section{INTRODUCTION}

Catathelasma imperiale (Fr.) Sing. (Tricholomataceae) is a coniferloving basidiomycete defined by its large size, white spore print, sticky brownish cap, mealy odor and double ring. This mushroom is mainly distributed in the southwest of China. Only a few ergosterols have been reported from the chemical investigation of this fungus. ${ }^{1}$ As a part of our efforts to discover the structurally diverse and biologically active secondary metabolites from higher fungi, ${ }^{2-5}$ the investigation of the fruiting bodies of $C$. imperiale has led to the isolation of five new compounds, catathelasmols A-E (1-5). Herein, details of the isolation and structural elucidation of $\mathbf{1 - 5}$ are described, including assignment of the absolute configurations by computational chemistry. Among them, compounds 3-5 showed inhibitory activities against two isozymes of $11 \beta$-hydroxysteroid dehydrogenases (11ß-HSD1 and $11 \beta$-HSD2), which catalyze the interconversion of cortisol and cortisone. Although these secondary metabolites are structurally simple, there are very few reports on these types of natural products.

\section{MATERIALS AND METHODS}

General

Optical rotations were obtained on a Horiba SEPA-300 polarimeter (Horiba, Tokyo, Japan). IR spectra were taken on a Bruker Tensor 27 FT-IR spectrometer (Bruker $\mathrm{GmbH}$, Ettlingen, Germany) with $\mathrm{KBr}$ pellets. NMR spectra were recorded with a Bruker DRX-500 instrument (Bruker $\mathrm{GmbH}$ ) in $\mathrm{CDCl}_{3}$
$\left(\delta_{\mathrm{H}}=7.26\right.$ p.p.m., $\delta_{\mathrm{C}}=77.00$ p.p.m. $)$ at room temperature. EI-MS, electrospray ionization mass spectrum (ESI-MS) and high resolution electrospray ionization mass spectrum (HR-ESI-MS) were measured on Finnigan-MAT 90 (Finnigan, Somerset, NJ, USA) and API QSTAR Pulsar i (MDS Sciex, Concord, ON, Canada) mass spectrometers, respectively. Silica gel (200-300 mesh; Qingdao Marine Chemical Inc., Qingdao, China) and Sephadex LH-20 (Amersham Biosciences, Uppsala, Sweden) were used for column chromatography. Fractions were monitored by TLC and spots were visualized by heating silica gel plates sprayed with vanillin- $\mathrm{H}_{2} \mathrm{SO}_{4}$ in ethanol.

\section{Fungus material}

The fresh fruiting bodies of $C$. imperiale were purchased at a market in Nanhua County of Yunnan Province, China, in August 2005 and were identified by Professor Mu Zang. The voucher specimen (HFG 05112) was deposited in the herbarium of Kunming Institute of Botany, Chinese Academy of Sciences.

\section{Extraction and isolation}

The dry fruiting bodies of $C$. imperiale $(700 \mathrm{~g}$ ) were extracted thrice with EtOAc (total 9l) at room temperature for 3 days each time. The extract was filtered and concentrated under reduced pressure to give a residue $(18.8 \mathrm{~g})$, which was subjected to silica gel column chromatography eluted with $\mathrm{CHCl}_{3} / \mathrm{MeOH}$ (from 100:0 to 0:100). The fraction $(6.6 \mathrm{~g})$ eluted with pure $\mathrm{CHCl}_{3}$ was subjected to further silica gel column chromatography using a gradient of petroleum ether:acetone $(150: 1 ; 50: 1 ; 20: 1)$ followed by pure $\mathrm{MeOH}$ to give subfractions A-D. Subfraction A (300 mg) (petroleum ether:acetone 150:1, v/v) was further isolated over a silica gel column eluted with petroleum ether:

\footnotetext{
${ }^{1}$ State Key Laboratory of Phytochemistry and Plant Resources in West China, Kunming Institute of Botany, Chinese Academy of Sciences, Kunming, China; ${ }^{2}$ Shanghai Institute of Materia Medica, Chinese Academy of Sciences, Shanghai, China; ${ }^{3}$ Graduate University of Chinese Academy of Sciences, Beijing, China and ${ }^{4}$ BioBioPha Co., Ltd, Kunming, China

Correspondence: Professor Dr J-K Liu, State Key Laboratory of Phytochemistry and Plant Resources in West China, Kunming Institute of Botany, Chinese Academy of Sciences, Kunming 650204, China.

E-mail: jkliu@mail.kib.ac.cn or Dr Y Leng, Shanghai Institute of Materia Medica, Chinese Academy of Sciences, Shanghai 201203, China.

E-mail: yleng@mail.shcnc.ac.cn
}

Received 22 October 2008; revised 12 February 2009; accepted 17 February 2009; published online 27 March 2009 
acetone (150:1) to give a residue $(160 \mathrm{mg}$ ) mainly containing $\mathbf{1}$ and 2 , which was repeatedly subjected to silica gel column chromatography to yield $\mathbf{1}$ $(40.0 \mathrm{mg})$ and $2(1.7 \mathrm{mg})$. Subfraction B $(180 \mathrm{mg})$ (petroleum ether:acetone $50: 1, \mathrm{v} / \mathrm{v}$ ), containing mainly 3 and $\mathbf{4}$, was further isolated on a silica gel column eluted with $\mathrm{CHCl}_{3}$ to yield $3(14.6 \mathrm{mg})$ and $\mathbf{4}(74.1 \mathrm{mg})$. Subfraction D $(121 \mathrm{mg})$ eluted with $\mathrm{MeOH}$ was purified by Sephadex $\mathrm{LH}-20\left(\mathrm{CHCl}_{3} / \mathrm{MeOH}\right.$ $1: 1, \mathrm{v} / \mathrm{v})$ and silica gel column chromatography using $\mathrm{CHCl}_{3} / \mathrm{MeOH}(150: 1$, $\mathrm{v} / \mathrm{v})$ as the eluent, to yield $\mathbf{5}(61.4 \mathrm{mg})$.

\section{Computational methods}

The stable geometries of $\mathbf{1}$ with low energy were investigated using HyperChem 7.0 (HyperCube, Gainesville, FL, USA). These low-energy conformations were then optimized at the B3LYP/6-31G (d) level again. The B3LYP/6-31G (d)optimized structures were then used for optical rotation calculations at the B3LYP/aug-cc-pVDZ//6-31+G (d). The calculated optical rotation for $(R)$ configuration was $+14.5^{\circ}$. This value is very close to the experimental magnitude of $+10.6^{\circ}$. Thus, the absolute configuration of $(+)-\mathbf{1}$ was assigned as $(R)$. Compound $\mathbf{5}$ has a linear structure and it is difficult to use the above method to compute its optical rotation to determine the absolute configuration. Our recent matrix method was used in the study. The value of the determinant $(\operatorname{det}(D))$ for $(R)-5$ was -2.50 . According to the principle of matrix prediction, the $\operatorname{det}(D)$ and $k_{0}$ value were needed to use both. As the optical rotation was $-10.4\left(c 0.40, \mathrm{CHCl}_{3}\right)$, the calculated $k_{0}$ value for this chiral secondary alcohol was 4.2, which is located in the window of coefficients of chiral secondary alcohols in chloroform. Thus, compound $\mathbf{5}$ was assigned $(R)$ configuration.

\section{Physicochemical properties}

Catathelasmol A (1): amorphous powder; $[\alpha]_{\mathrm{D}}^{26}+10.6$ (c 0.30, $\left.\mathrm{CHCl}_{3}\right)$; IR (KBr): $3450,1175,1115,1058,1033 \mathrm{~cm}^{-1} ;{ }^{1} \mathrm{H}-$ and ${ }^{13} \mathrm{C}-\mathrm{NMR}$ : see Table 1; ESI-MS (pos.): $101\left[\mathrm{M}-\mathrm{H}_{2} \mathrm{O}+\mathrm{H}\right]^{+}, 83\left[\mathrm{M}-2 \mathrm{H}_{2} \mathrm{O}+\mathrm{H}\right]^{+}$; HR-ESI-MS (pos.): $101.0600\left(\left[\mathrm{M}-\mathrm{H}_{2} \mathrm{O}+\mathrm{H}\right]^{+}\right.$, calcd. 101.0602).

Catathelasmol B (2): colorless oil; $[\alpha]_{\mathrm{D}}^{26}+8.9\left(\right.$ c $\left.0.30, \mathrm{CHCl}_{3}\right)$; IR $(\mathrm{KBr})$ : 3441, 1191, 1167, 1104, 1062, $1034 \mathrm{~cm}^{-1}$; ${ }^{1} \mathrm{H}-$ and ${ }^{13} \mathrm{C}-\mathrm{NMR}$ : see Table 1; ESIMS (pos.): $218[\mathrm{M}]^{+}, 201\left[\mathrm{M}-\mathrm{H}_{2} \mathrm{O}+\mathrm{H}\right]^{+}, 183\left[\mathrm{M}-2 \mathrm{H}_{2} \mathrm{O}+\mathrm{H}\right]^{+}$; HR-ESI-MS (pos.): $201.1125\left(\left[\mathrm{M}-\mathrm{H}_{2} \mathrm{O}+\mathrm{H}\right]^{+}\right.$, calcd. 201.1126).

Catathelasmol C (3): colorless oil; IR (KBr): 1736, 1661, 1371, 1236, $1191 \mathrm{~cm}^{-1} .{ }^{1} \mathrm{H}-$ and ${ }^{13} \mathrm{C}-\mathrm{NMR}$ : see Table 2; ESI-MS (pos.): $225[\mathrm{M}+\mathrm{Na}]^{+}$; HR-ESI-MS (pos.): 225.0739 ([M+Na $]^{+}$, calcd. 225.0738).

Catathelasmol D (4): colorless oil; IR (KBr): 3441, 2966, 1738, 1369, 1248, $1045 \mathrm{~cm}^{-1} ;{ }^{1} \mathrm{H}$ - and ${ }^{13} \mathrm{C}-\mathrm{NMR}$ : see Table 2; EI-MS: $160\left(\mathrm{M}^{+}, 2\right), 129(42), 112$ (17), 100 (14), 87 (100); HR-FAB-MS (pos.): 161.0838 ([M+H $]^{+}$, calcd. 161.0814).

Catathelasmol E (5): colorless oil; $[\alpha]_{\mathrm{D}}^{26}-10.4\left(\right.$ c $\left.0.40, \mathrm{CHCl}_{3}\right)$; IR $(\mathrm{KBr})$ : 3458, 1740, 1450, $1247 \mathrm{~cm}^{-1}$. ${ }^{1} \mathrm{H}$ - and ${ }^{13} \mathrm{C}-\mathrm{NMR}$ : see Table 2; ESI-MS (pos.): $227[\mathrm{M}+\mathrm{Na}]^{+}$; HR-ESI-MS (pos.): $227.0889\left([\mathrm{M}+\mathrm{Na}]^{+}\right.$, calcd. 227.0895).

\section{Biological testing}

The inhibitory activities of the compounds on human or mouse 11ß-HSD1 and $11 \beta-\mathrm{HSD} 2$ enzymatic activities were determined by the scintillation proximity assay using microsomes containing $11 \beta$-HSD1 or $11 \beta$-HSD2, according to our earlier studies. ${ }^{6}$ Briefly, the full-length cDNAs of human or murine $11 \beta-H S D 1$ and $11 \beta-H S D 2$ were isolated from the cDNA libraries provided by the NIH Mammalian Gene Collection and cloned into pcDNA3 expression vector. HEK-293 cells were transfected with the pcDNA3-derived expression plasmid and selected by cultivation in the presence of $700 \mu \mathrm{g} \mathrm{ml}^{-1}$ of G418. The microsomal fraction overexpressing $11 \beta$-HSD1 or $11 \beta-H S D 2$ was prepared from the HEK-293 cells stably transfected with either 11 $\beta$-HSD1 or $11 \beta-H S D 2$ and was used as the enzyme source for scintillation proximity assay. Microsomes containing human or mouse $11 \beta-H S D 1$ were incubated with NADPH and $\left[{ }^{3} \mathrm{H}\right]$ cortisone. Then the product, $\left[{ }^{3} \mathrm{H}\right]$ cortisol, was specifically captured by a monoclonal antibody coupled to protein A-coated scintillation proximity assay beads. The $11 \beta-\mathrm{HSD} 2$ screening was performed by incubating $11 \beta$-HSD2 microsomes with $\left[{ }^{3} \mathrm{H}\right]$ cortisol and $\mathrm{NAD}^{+}$and monitoring substrate disappearance. $\mathrm{IC}_{50}$ values were calculated by using Prism Version 4 (GraphPad Software, San Diego, CA, USA).

\section{RESULTS AND DISCUSSION}

Catathelasmol A (1), obtained as an amorphous powder, has a molecular formula of $\mathrm{C}_{5} \mathrm{H}_{10} \mathrm{O}_{3}$ based on the positive-ion HR-ESIMS, showing a quasi-molecular ion peak at $\mathrm{m} / z$ 101. 0600 (calcd. for $\left.\left[\mathrm{C}_{5} \mathrm{H}_{10} \mathrm{O}_{3}-\mathrm{H}_{2} \mathrm{O}+\mathrm{H}\right]^{+}, 101.0602\right)$ and requiring only one degree of unsaturation. The IR spectrum showed the presence of one or more hydroxyl groups $\left(3450 \mathrm{~cm}^{-1}\right)$. The ${ }^{13} \mathrm{C}-\mathrm{NMR}$ spectrum (Table 1 ) exhibited five signals: one quaternary carbon bearing two oxygens at $\delta$ 102.7, two oxymethylenes at $\delta 68.0(\mathrm{t}), 65.2(\mathrm{t})$ and two up-field methylenes at $\delta 33.8(\mathrm{t}), 23.5(\mathrm{t})$. It was obvious that only one degree of unsaturation was attributed to a ring. The ${ }^{1} \mathrm{H}-\mathrm{NMR}$ spectrum (Table 1 ) showed eight protons: two oxygenated methylenes at $\delta 3.45(1 \mathrm{H}, \mathrm{d}, J=11.5 \mathrm{~Hz}), 4.14$ $(1 \mathrm{H}, \mathrm{d}, J=11.5 \mathrm{~Hz}), 3.97(2 \mathrm{H}, \mathrm{t}, J=6.9 \mathrm{~Hz})$, and up-field resonances at $\delta$ $1.61(1 \mathrm{H}, \mathrm{m}), 1.94(1 \mathrm{H}, \mathrm{m}), 1.88(1 \mathrm{H}, \mathrm{m}), 2.05(1 \mathrm{H}, \mathrm{m})$. The above NMR data suggested that 1 possessed a tetrahydrofuran moiety connected with a hydroxyl and a hydroxymethyl group. The heteronuclear multi-bond correlations (HMBC) (Figure 1) from H-6 to C-2 and C-3, and from $\mathrm{H}-5$ to $\mathrm{C}-2$ and $\mathrm{C}-3$ were observed; consequently, the hydroxyl and hydroxymethyl groups were doubtless both emplaced at $\mathrm{C}-2$. The absolute configuration of $(+)-1$ was assigned as $(R)$ using the B3LYP/aug-cc-pVDZ//6-31+G(d) methods ${ }^{7-9}$ based on the comparison of experimental optical rotation $\left(+10.6^{\circ}\right)$ and calculated optical rotation $\left(+14.5^{\circ}\right)$. Therefore, the structure of $\mathbf{1}$ was determined as $(R)-(+)-$ 2-(hydroxymethyl)-tetrahydrofuran-2-ol and named catathelasmol A, as shown in Figure 2.

Catathelasmol B (2), a colorless oil, was obtained as a minor constituent with a molecular formula of $\mathrm{C}_{10} \mathrm{H}_{18} \mathrm{O}_{5}$, based on the positive-ion HR-ESI-MS: 201.1125 (calcd. for $\left[\mathrm{C}_{10} \mathrm{H}_{18} \mathrm{O}_{5}-\mathrm{H}_{2} \mathrm{O}+\mathrm{H}\right]^{+}$, 201.1126). In the NMR spectra (Table 1 ) of 2 , signals for the number of protons and carbon that were observed were only half of the number that would correspond to the molecular formula. This indicated that 2 is a symmetrical structure. The NMR data were considerably in accordance with those of 1 , but their TLC behavior was discriminable, which suggested that $\mathbf{2}$ was unambiguously a dimer of 1 , and there were just two possible condensed positions: C-2 or C-6 hydroxyl. There was no reaction and no corresponding product obtained in acetylation, which suggested that there was no free

Table 1 NMR spectral data for compounds 1 and 2 in $\mathrm{CDCl}_{3}$

1

No.

$\delta_{H}$

\begin{tabular}{rrrrr} 
& \multicolumn{1}{c}{$\delta_{C}$} & \multicolumn{1}{l}{$\delta_{H}$} & $\delta_{C}$ & $\delta_{H}$ \\
\hline 2 & $102.7(\mathrm{~s})$ & & $103.8(\mathrm{~s})$ & \\
3 & $33.8(\mathrm{t})$ & $1.61,1.94($ each $1 \mathrm{H}, \mathrm{m})$ & $33.7(\mathrm{t})$ & $1.77,2.11($ each $1 \mathrm{H}, \mathrm{m})$ \\
4 & $23.5(\mathrm{t})$ & $1.88,2.05($ each $1 \mathrm{H}, \mathrm{m})$ & $24.1(\mathrm{t})$ & $1.89,2.03($ each $1 \mathrm{H}, \mathrm{m})$ \\
5 & $68.0(\mathrm{t})$ & $3.97(2 \mathrm{H}, 6.9)$ & $67.9(\mathrm{t})$ & $3.94,4.00($ each $1 \mathrm{H}, \mathrm{m})$ \\
6 & $65.2(\mathrm{t})$ & $3.45(1 \mathrm{H}, \mathrm{d}, 11.5), 4.14(1 \mathrm{H}, \mathrm{d}, 11.5)$ & $66.3(\mathrm{t})$ & $3.55(1 \mathrm{H}, \mathrm{d}, 11.8), 3.94(1 \mathrm{H}, \mathrm{d}, 11.8)$ \\
\hline
\end{tabular}


Table 2 NMR spectral data for compounds 3-5 in $\mathrm{CDCl}_{3}$

\begin{tabular}{|c|c|c|c|c|c|c|}
\hline \multirow{2}{*}{ No. } & \multicolumn{2}{|c|}{3} & \multicolumn{2}{|r|}{4} & \multicolumn{2}{|r|}{5} \\
\hline & $\delta_{C}$ & $\delta_{H}$ & $\delta_{C}$ & $\delta_{H}$ & $\delta_{C}$ & $\delta_{H}$ \\
\hline 1 & $67.9(\mathrm{t})$ & $4.65(2 \mathrm{H}, \mathrm{s})$ & $63.1(\mathrm{t})$ & $4.26(2 \mathrm{H}, \mathrm{s})$ & $68.6(t)$ & $3.95(1 \mathrm{H}, \mathrm{dd}, 11.3,7.2), 4.11(1 \mathrm{H}, \mathrm{dd}, 11.3,7.2)$ \\
\hline 2 & 202.9 (s) & & 208.9 (s) & & $69.3(d)$ & $3.84(1 \mathrm{H}, \mathrm{m})$ \\
\hline 3 & $35.1(\mathrm{t})$ & $2.50(2 \mathrm{H}, \mathrm{t}, 7.2)$ & $34.4(\mathrm{t})$ & $2.52(2 \mathrm{H}, \mathrm{t}, 7.2)$ & $29.6(t)$ & $1.71,1.80($ each $1 \mathrm{H}, \mathrm{m})$ \\
\hline 4 & $22.2(t)$ & $1.95(2 \mathrm{H}, \mathrm{m})$ & $22.3(t)$ & $1.97(2 \mathrm{H}, \mathrm{m})$ & $24.6(t)$ & $1.52(2 \mathrm{H}, \mathrm{m})$ \\
\hline 5 & $66.3(t)$ & $4.06(2 \mathrm{H}, \mathrm{t}, 6.3)$ & $67.8(t)$ & $4.08(2 \mathrm{H}, \mathrm{t}, 6.3)$ & $64.2(t)$ & $4.08(2 \mathrm{H}, \mathrm{t}, 6.5)$ \\
\hline$a_{1}$ & $170.2(\mathrm{~s})$ & & & & $171.3(\mathrm{~s})$ & \\
\hline$a_{2}$ & $20.4(q)$ & $2.16(3 \mathrm{H}, \mathrm{s})$ & & & $20.9(q)$ & $2.08(3 \mathrm{H}, \mathrm{s})$ \\
\hline $\mathrm{b}_{1}$ & $171.0(\mathrm{~s})$ & & 170.9 (s) & & $171.3(\mathrm{~s})$ & \\
\hline$b_{2}$ & $20.9(q)$ & $2.04(3 \mathrm{H}, \mathrm{s})$ & $20.5(q)$ & $2.04(3 \mathrm{H}, \mathrm{s})$ & $21.0(q)$ & $2.03(3 \mathrm{H}, \mathrm{s})$ \\
\hline
\end{tabular}

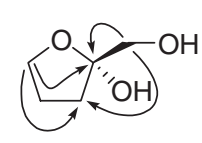

1

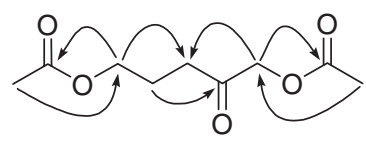

3

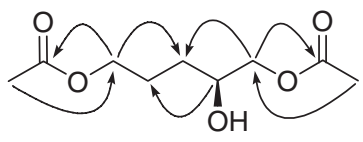

5

Figure 1 Key HMBC correlations of compounds $\mathbf{1}, \mathbf{3}$ and $\mathbf{5}$.

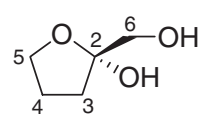

1<smiles>O[C@@]1(COC[C@@]2(O)CCCO2)CCCO1</smiles>

2<smiles>CC(=O)OCCCC(=O)COC(C)=O</smiles>

3<smiles>CC(=O)OCCCC(=O)CO</smiles>

4<smiles>CC(=O)OCCCC(O)COC(C)=O</smiles>

5

Figure 2 Structures of compounds 1-5.

primary hydroxyl group in the structure of $\mathbf{2}$, but that $\mathbf{2}$ was formed from two molecules of 1 through the intermolecular dehydration at C-6 hydroxyl. Thus, the structure of 2 was proposed as $\left(2 R, 2^{\prime} R\right)-2,2^{\prime}-$ oxybis(methylene)bis(tetrahydrofuran-2-ol), as shown in Figure 2.

Catathelasmol C (3) was isolated as a colorless oil possessing the molecular formula $\mathrm{C}_{9} \mathrm{H}_{14} \mathrm{O}_{5}$, based on the positive-ion HR-ESI-MS: 225.0739 (calcd. for $\mathrm{C}_{9} \mathrm{H}_{14} \mathrm{O}_{5} \mathrm{Na}, 225.0738$ ). The IR spectrum showed the absorption bands of ester carbonyl $\left(1736 \mathrm{~cm}^{1}\right)$ and keto carbonyl $\left(1661 \mathrm{~cm}^{-1}\right)$ groups. The ${ }^{13} \mathrm{C}-\mathrm{NMR}$ spectrum (Table 2$)$ exhibited nine carbon resonances, including one keto carbonyl at $\delta 202.9$ (s), two oxymethylenes at $\delta 67.9(\mathrm{t}), 66.3(\mathrm{t})$, two up-field methylene carbons at $\delta 35.1(\mathrm{t}), 22.2(\mathrm{t})$, as well as characteristic signals at $\delta 170.2(\mathrm{~s}), 20.4$ (q); 171.0 (s), 20.9 (q) contributed to two acetoxyls. The ${ }^{1} \mathrm{H}-\mathrm{NMR}$ spectrum (Table 2) of $\mathbf{3}$ showed signals for two oxygenated methylenes at $\delta 4.65(2 \mathrm{H}, \mathrm{s}), 4.06(2 \mathrm{H}, \mathrm{t}, J=6.3 \mathrm{~Hz})$, two up-field methylenes at $\delta$ $2.50(2 \mathrm{H}, \mathrm{t}, J=7.2 \mathrm{~Hz}), 1.95(2 \mathrm{H}, \mathrm{m})$ together with two acetoxyl methyl singlets at $\delta 2.16(3 \mathrm{H}, \mathrm{s}), 2.04(3 \mathrm{H}, \mathrm{s})$. The above NMR character allowed us to conclude that $\mathbf{3}$ was a diacetylated pentanediol containing a keto group. By analysis of the HMBC spectrum (Figure 1), the position of the ketone was determined at $\mathrm{C}-2$, in which the correlations from $\mathrm{H}-1$ to $\mathrm{C}-3$ and $\mathrm{C}-\mathrm{a}_{1}$, from $\mathrm{H}-5$ to $\mathrm{C}-3$ and $\mathrm{C}-\mathrm{b}_{1}$ and from H-4 to C-2 were observed. Therefore, the structure of 3 was elucidated as 2-oxopentane-1,5-diyl diacetate named catathelasmol C, which was a new natural product. ${ }^{10}$

Catathelasmol D (4), also obtained as a colorless oil, has a molecular formula of $\mathrm{C}_{7} \mathrm{H}_{12} \mathrm{O}_{4}$, based on the EI-MS showing a molecular ion peak at $m / z 160$, in combination with the ${ }^{13} \mathrm{C}-\mathrm{NMR}$ (DEPT) spectrum. The NMR data (Table 2) of 4 were similar to those of 3, but there was only one set of acetoxyl signals: $\delta 170.9$ (s), 20.5 (q). Considering that the signal at $\delta 4.26(2 \mathrm{H}, \mathrm{s}, \mathrm{H}-1)$ in 4 evidently shifted up-field ( $\delta=0.39$ p.p.m.) compared with that of 3 , the acetoxyl group must be connected at C-5 in 4 . Thus, the structure of 4 was determined as 5-hydroxy-4-oxopentyl acetate and named catathelasmol D, which was also a new natural product, ${ }^{11}$ as shown in Figure 2.

Catathelasmol E (5), a colorless oil, was assigned the molecular formula $\mathrm{C}_{9} \mathrm{H}_{16} \mathrm{O}_{5}$ by the positive-ion HR-ESI-MS: 227.0889 (calcd. for $\left.\mathrm{C}_{9} \mathrm{H}_{16} \mathrm{O}_{5} \mathrm{Na}, 227.0895\right)$. The NMR data of $\mathbf{5}$ were similar to those of $\mathbf{3}$, and comparison of ${ }^{13} \mathrm{C}-\mathrm{NMR}$ data showed that instead of a ketone, one oxymethine carbon at $\delta 69.3$ (d) newly appeared in 5 . The obvious differences in the ${ }^{1} \mathrm{H}-\mathrm{NMR}$ spectra were as follows: (a) the oxymethylene singlet in $\mathbf{3}$ was observed separately from each other at $\delta$ $3.95(1 \mathrm{H}, \mathrm{dd}, J=11.3,7.2 \mathrm{~Hz})$ and $4.11(1 \mathrm{H}, \mathrm{dd}, J=11.3,7.2 \mathrm{~Hz})$, 


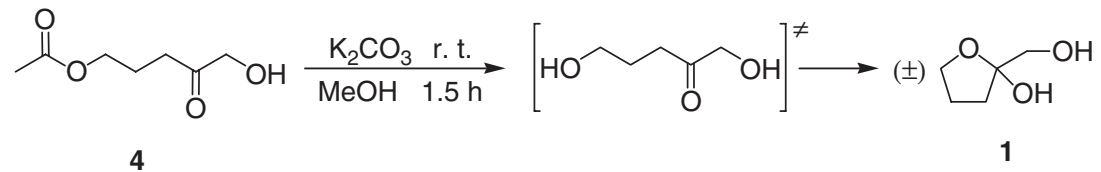

Figure 3 Chemical transformation from 4 to 1 .

respectively in 5; and (b) an oxygen-bearing methine proton at $\delta 3.84$ $(1 \mathrm{H}, \mathrm{m})$ was newly detected in $\mathbf{5}$. The above NMR character indicated that the keto group in $\mathbf{3}$ was hydrogenated in $\mathbf{5}$. Initially, the modified Mosher's method ${ }^{12,13}$ was applied to determine the absolute configuration of the hydroxyl at C-2, but failed. Alternatively, we resorted to the computational method to establish the absolute configuration. The absolute configuration of $\mathbf{5}$ was assigned as $(R)$ using matrix model. ${ }^{14}$ The $\operatorname{det}(D)$ value for this chiral alcohol was -2.50 and the calculated $k_{0}$ value was 4.2 , which is located in the window of coefficients of chiral secondary alcohols in chloroform. Accordingly, the structure of $\mathbf{5}$ was established as 2-hydroxypentane-1,5-diyl diacetate, shown in Figure 2, and was named catathelasmol E.

It was not until quite recently that such simple pentanol derivatives were found, which suggested that this type of metabolites were distributed in a narrow range, so we believe that they may possess an important chemotaxonomic significance. Besides, the realization of the chemical transformation from $\mathbf{4}$ to $\mathbf{1}$ validated the structural correctness (Figure 3).

Chemical transformation from 4 to $1:^{15}$ A solution of $4(50 \mathrm{mg})$ in $\mathrm{MeOH}(5.0 \mathrm{ml})$ was treated with $\mathrm{K}_{2} \mathrm{CO}_{3}(97.4 \mathrm{mg})$ at room temperature. After stirring for $1.5 \mathrm{~h}$, saturated aqueous ammonium chloride was added and extracted with ethyl acetate, and the organic layer was washed with water and brine, dried over sodium sulfate, and evaporated to a residue that was purified by a silica gel column using pure $\mathrm{CHCl}_{3}$ to yield $1(12 \mathrm{mg})$. The determined optical rotation was expectedly zero. Thus, the cyclization of $\mathbf{4}$ to $\mathbf{1}$ obtained in the experiments must involve the enzyme catalysis.

Glucocorticoid hormones play important roles in many biological and physiological processes, including regulation of energy metabolism, inflammatory, immune and stress responses, and cardiovascular homeostasis. The action of glucocorticoid on target tissue is not dependent inevitably on the circulating levels, but is regulated in a tissue-specific manner by the enzymes of $11 \beta$-hydroxysteroid dehy-

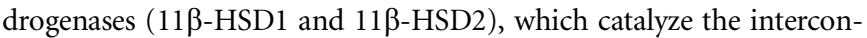
version of active 11-hydroxy-glucocorticoids (cortisol in humans and corticosterone in rodents) and their respective inert 11-keto forms (cortisone in humans and 11-dehydrocorticosterone in rodents). ${ }^{16}$ $11 \beta$-HSD1 is highly expressed in the liver, gonad, adipose tissue and brain, in which it acts as a reductase regenerating the active glucocorticoids from its inactive forms, thus amplifying local glucocorticoid action. ${ }^{17} 11 \beta$-HSD2 is predominantly expressed in aldosterone target cells, such as the kidney and colon, in which it catalyzes the inactivation of glucocorticoids, thereby preventing the excessive activation of the mineralocorticoid receptor and sequelae, including sodium retention, hypokalemia and hypertension.

We tested the inhibitory effect of the compounds on both human and mouse $11 \beta$-HSD1 and 11 $\beta$-HSD2. Compound 3 showed inhibitory activities against $11 \beta$-HSD1 (human $\mathrm{IC}_{50}=28.7 \mu \mathrm{g} \mathrm{ml}^{-1}$; mouse $\mathrm{IC}_{50}=30.4 \mu \mathrm{g} \mathrm{ml}^{-1}$ ) and $11 \beta$-HSD2 (human $\mathrm{IC}_{50}=5.1 \mu \mathrm{g} \mathrm{ml}^{-1}$; mouse
$\left.\mathrm{IC}_{50}=32.3 \mu \mathrm{g} \mathrm{ml}^{-1}\right)$. Compound 4 showed inhibitory activities against $11 \beta$-HSD1 (human $\mathrm{IC}_{50}=47.4 \mu \mathrm{g} \mathrm{ml}^{-1}$; mouse $\mathrm{IC}_{50}=$ $149.2 \mu \mathrm{g} \mathrm{ml}^{-1}$ ) and $11 \beta$-HSD2 (human $\mathrm{IC}_{50}=38.9 \mu \mathrm{g} \mathrm{ml}^{-1}$; mouse $\mathrm{IC}_{50}=129.1 \mu \mathrm{g} \mathrm{ml}^{-1}$ ). Compound $\mathbf{5}$ showed inhibitory activities against human $11 \beta$-HSD1 $\left(\mathrm{IC}_{50}=62.3 \mu \mathrm{g} \mathrm{ml}^{-1}\right)$ and $11 \beta$-HSD2 $\left(\mathrm{IC}_{50}=177.0 \mu \mathrm{g} \mathrm{ml}^{-1}\right)$. Therefore, compounds 3-5 showed inhibitory activities against $11 \beta-\mathrm{HSD} 1$ and $11 \beta-\mathrm{HSD} 2$ and provide the possibility for modulating local cortisone/cortisol availability in vivo.

\section{ACKNOWLEDGEMENTS}

This project was supported by National Basic Research Program of China (973 Program, 2009CB522300), National Natural Science Foundation of China (30830113) and Chinese Academy of Sciences (KSCX1-YW-R-24; KSCX2-YW-G-025)

1 Yang, S. P., Xu, J. \& Yue, J. M. Sterols from the fungus Catathelasma imperiale. Chin. J. Chem. 21, 1390-1394 (2003).

2 Liu, J. K. N-containing compounds of macromycetes. Chem. Rev. 105, 2723-2744 (2005).

3 Liu, J. K. Natural terphenyls: developments since 1877. Chem. Rev. 106, 2209-2223 (2006).

4 Zhou, Z. Y. et al. Gallicynoic acids A-I, acetylenic acids from the Basidiomycete Coriolopsis gallica. J. Nat. Prod. 71, 223-226 (2008).

5 Zhang, L., Wang, F., Dong, Z. J., Steglich, W. \& Liu, J. K. A new butenolide-type fungal pigment from the mushroom Pulveroboletus ravenelii. Heterocycles 68, 1455-1458 (2006).

6 Yang, H. Y., Dou, W., Lou, J., Leng, Y. \& Shen, J. H. Discovery of novel inhibitors of 11 beta-hydroxysteroid dehydrogenase type 1 by docking and pharmacophore modeling. Bioorg. Med. Chem. Lett. 18, 1340-1345 (2008)

7 Liu, D. Z. et al. Vibralactone: a lipase inhibitor with an unusual fused beta-lactone produced by cultures of the basidiomycete Boreostereum vibrans. Org. Lett. 8, 57495752 (2006).

8 Amos, R. D. Electric and magnetic properties of $\mathrm{CO}, \mathrm{HF}, \mathrm{HCl}$, and $\mathrm{CH}_{3} \mathrm{~F}$. Chem. Phys. Lett. 87, 23-26 (1982)

9 Polavarapu, P. L. Ab initio molecular optical rotations and absolute configurations. Mol. Phys. 91, 551-554 (1997).

10 Kuschinsky, G., Lange, G., Scholtissek, C. h. \& Turba, F. Reaction mechanism of digitalis constituents. Biochem. Z. 327, 314-330 (1955).

11 Bonini, C., Chiummiento, L., Funicello, M., Lupattelli, P. \& Pullez, M. New functionalized hydroxymethyl ketones from the mild and chemoselective $\mathrm{KMnO}_{4}$ oxidation of chiral terminal olefins. Eur. J. Org. Chem. 80-83 (2006).

12 Dale, J. A. \& Mosher, H. S. Nuclear magnetic resonance enantiomer regents. Configurational correlations via nuclear magnetic resonance chemical shifts of diastereomeric mandelate, 0 -methylmandelate, and $\alpha$-methoxy- $\alpha$-trifluoromethylphenylacetate (MTPA) esters. J. Am. Chem. Soc. 95, 512-519 (1973).

13 Ohtani, I., Kusumi, T., Kashman, Y. \& Kakisawa, H. High-field FT NMR application of Mosher's method. The absolute configurations of marine terpenoids. J. Am. Chem. Soc. 113, 4092-4096 (1991).

14 Zhu, H. J., Ren, J. \& Pittman, C. U. Matrix model to predict specific optical rotations of acyclic chiral molecules. Tetrahedron 63, 2292-2314 (2007).

15 Yiotakis, A., Magriotisb, P. A. \& Vassiliou, S. A simple synthesis of the metabotropic receptor ligand (2S)- $\alpha$-(hydroxymethyl)-glutamic acid and its Fmoc protected derivatives. Tetrahedron: Asymmetry 18, 873-877 (2007)

16 Stewart, P. M. \& Draper, N. 11ß-hydroxysteroid dehydrogenase and the pre-receptor regulation of corticosteroid hormone action. J. Endocrinol. 186, 251-271 (2005)

17 Seckl, J. R. \& Walker, B. R. Minireview: 11beta-hydroxysteroid dehydrogenase type 1-a tissue-specific amplifier of glucocorticoid action. Endocrinology 142, 1371-1376 (2001). 